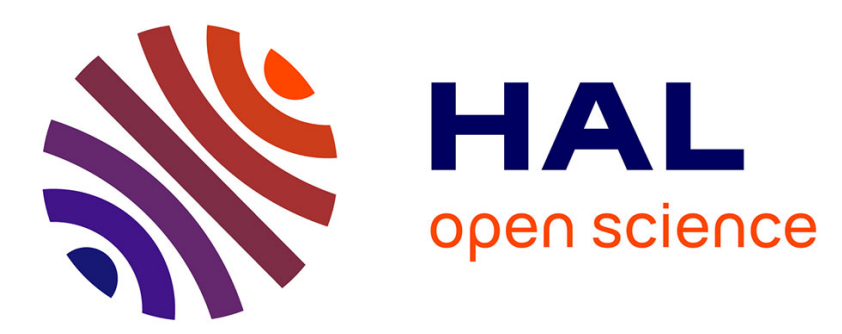

\title{
Fluorenyl dendrimer porphyrins: synthesis and photophysical properties
}

Samuel Drouet, Christine O Paul-Roth

\section{To cite this version:}

Samuel Drouet, Christine O Paul-Roth. Fluorenyl dendrimer porphyrins: synthesis and photophysical properties. Tetrahedron, 2009, 65 (51), pp.10693-10700. 10.1016/j.tet.2009.10.043 . hal-02945956

\section{HAL Id: hal-02945956 \\ https://hal-univ-rennes1.archives-ouvertes.fr/hal-02945956}

Submitted on 22 Sep 2020

HAL is a multi-disciplinary open access archive for the deposit and dissemination of scientific research documents, whether they are published or not. The documents may come from teaching and research institutions in France or abroad, or from public or private research centers.
L'archive ouverte pluridisciplinaire HAL, est destinée au dépôt et à la diffusion de documents scientifiques de niveau recherche, publiés ou non, émanant des établissements d'enseignement et de recherche français ou étrangers, des laboratoires publics ou privés. 


\section{Graphical Abstract}

\section{Fluorenyl Dendrimer Porphyrins: Synthesis and Photophysical Properties}

Samuel Drouet, Christine O. Paul-Roth*

Groupe Ingénierie Chimique \& Molécules pour le Vivant, INSA-SCR UMR CNRS 6226,

Université de Rennes I, 35042 Rennes cedex, France

Institut National des Sciences Appliquées-INSA de Rennes

*Corresponding author. Fax: 02232356 37; Tel.: 0223236372

e-mail: christine.paul@univ-rennes1.fr or christine.paul@insa-rennes.fr
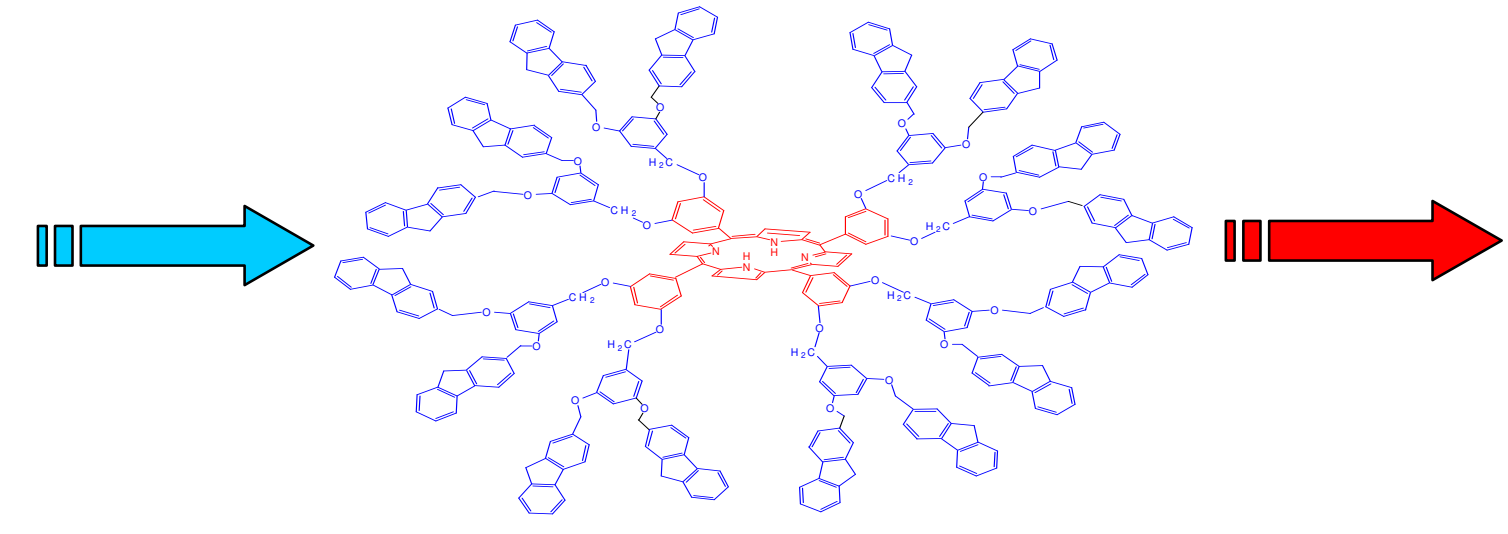


\title{
Fluorenyl Dendrimer Porphyrins: Synthesis and Photophysical Properties
}

\section{Samuel Drouet, Christine O. Paul-Roth*}

Groupe Ingénierie Chimique \& Molécules pour le Vivant, INSA-SCR UMR CNRS 6226,

Université de Rennes I, 35042 Rennes cedex, France

Institut National des Sciences Appliquées-INSA de Rennes

*Corresponding author. Fax: 022323 56 37; Tel.: 0223236372

e-mail: christine.paul@univ-rennes1.fr or christine.paul@insa-rennes.fr

\begin{abstract}
New symmetrical dendrimeric type super-porphyrin bearing sixteen fluorenyl donor groups sixteenfluorenylporphyrin SOFP (1) have been synthesized and characterized. Preliminary photophysical properties are reported; in comparison to the references first generation dendrimer tetrafluorenylporphyrin TOFP (2) bearing four peripheral fluorenyl and second generation dendrimer octafluorenylporphyrin OOFP (3) bearing eight peripheral fluorenyl, the luminescence properties are slightly improved. It is found that the excitation energy transfer occurs from the sixteen fluorenyl units to the porphyrin core, following what the porphyrin emits intense red light.
\end{abstract}

Keywords: Fluorescence; Porphyrins; fluorene, light harvesting, red emission

\section{Introduction}

There has been great interest in the synthesis of porphyrin systems because the peripheral substituent on the macrocyclic core can modulate the physical properties at will. Consequently, they present wide potential applications in different fields: such as for instance light-harvesting, Organic Light Emitting Diodes (OLEDs) or switches.

Light-harvesting can be optimized by attaching four energy donor dendrons to the porphyrin skeleton, to obtain an antenna system comprising a central porphyrin unit linked to four peripheral photon-harvesting hydrocarbon moieties. ${ }^{1,2,3}$ Recently a series of star-shaped 
porphyrins bearing pendant linear oligofluorene arms have been reported. ${ }^{4,5}$ Indeed, Fréchet $^{6}$ had demonstrated that the antenna effect was facilitated in dendritic architectures versus the corresponding linear case and reported the synthesis of porphyrin systems with modified fluorenyl units as light-harvesting two-photon absorbing chromophores. ${ }^{7,8}$ The same year, for tuning the optical properties of polymers, the synthesis of hyperbranched polymers containing porphyrin core possessing fluorenyl arms has also been reported. ${ }^{9}$

We have previously reported the synthesis of porphyrin possessing four fluorenyl arms directly connected at the meso-positions (TFP compound 4) and demonstrated that the ruthenium(II) complexes are efficient catalysts. ${ }^{10}$ More recently, we focused on the photophysical properties of such porphyrins ${ }^{11,12}$ and a complete family of relevant porphyrins was studied in collaboration with Williams. ${ }^{13}$ Surprisingly, this porphyrin TFP exhibited a high quantum yields (24\%), demonstrating the good capacity of the fluorenyl units to enhance quantum yields by increasing the radiative process. By the fact that TFP exhibits good red chromaticity and enhanced emission efficiency, it is interesting to incorporate this compound in the fabrication of Organic Light Emitting Diodes (OLEDs), this work is actually in progress. ${ }^{14}$ In this view, very recently, a density functional theory (DFT) study on photophysical properties of the complete family of porphyrin bearing fluorenyl arms synthesized by Paul-Roth was accomplished. ${ }^{15}$ This work, done by Ren and Col., provides some useful information for the charge carrier transport properties of high efficiency red lightemitting material by theoretical investigations.

The aim of the present work was to exploit this capacity of the fluorenyl arms to enhance further fluorescence. So the synthesis of a super porphyrin bearing sixteen peripheral fluorenyl groups is proposed and compared to the references first generation molecule bearing four units (TOFP) and second generation bearing eight units (OFP). The target is to obtain highly luminescent soluble organic compounds, by the design of porphyrin possessing fluorenyl arms using Fréchet's style dendritic strategy. In more details, in this paper, we present systems in which a 5,10,15,20-tetraphenylporphyrin (TPP) is linked, via ether bridges, to four, eight and sixteen fluorenyl donor moieties, compounds $\mathbf{2}, \mathbf{3}$ and $\mathbf{1}$ respectively (Fig. 1), and in a second part preliminary photophysical results are reported and compared to previous data of these compounds in order to understand better the energy transfer between the fluorenyl units and the macrocyclic core.

(Insert Fig. 1 here please) 


\section{Results and discussion}

\subsection{Synthesis}

The synthetic strategy developed for the preparation of these dendrimeric compounds is a Frechet's style condensation. First the porphyrin possessing eigth anchoring points is synthesised as well as the new dendron 10. In a second time, four of these dendrons are connected to the mother porphyrin core.

\section{(Insert Scheme 1 here please)}

In more details, the intermediate porphyrin 7 (OOHPP), was obtained from the prepared methylated porphyrin analog, porphyrin $6(\mathbf{O O M e P P})$ by reaction with $\mathrm{BBr}_{3}$ as illustrated in Scheme 1. ${ }^{16}$ The 2-hydroxyl-methyl-fluorene was obtained by reduction of commercial fluorene-2-carboxaldehyde and the corresponding alcohol was then brominated with carbon tetrabromide to obtain 2-bromo-methyl-fluorene 8. The detailed synthesis of these building blocks was described earlier. ${ }^{17}$ First the alcoholic form of the dendron 9 was obtained by condensation from the previous prepared bromide $\mathbf{8}$ and from commercial 5-hydroxymethylbenzen-1,3-diol in acetone using potassium carbonate as a base in presence of 18-crown-6 (Scheme 2). Finally, the intermediate dendron 9 was obtained pure as a white solid after purification in $71 \%$ yield. The alcohol 9 was then brominated with carbon tetrabromide in THF and the desired brominated dendron $\mathbf{1 0}$ was obtained pure as a white solid after flash chromatography in $80 \%$ yield.

\section{(Insert Scheme 2 here please)}

The target super-porphyrin 1 (Figure 1), containing sixteen absorbing donor chromophores in a multivalent dendritic configuration was eventually synthesized from the prepared bromide dendron 10 (10 eq) and OOHPP 7 (1 eq) in dry THF using potassium carbonate as a base in presence of 18-crown-6 (Scheme 2). The fixation of all sixteen donor chromophores in compound $\mathbf{1}$ was confirmed by matrix-assisted laser desorption ionization time-of-flight mass spectrometry (MALDI-TOF MS) as well as by NMR. The hydrogen and carbon atom-labeling scheme for the porphyrin ligand $\mathbf{1}$ as well as for dendron $\mathbf{9}$ and $\mathbf{1 0}$ are shown in Figure 6. Compound $\mathbf{1}$ is soluble in most organic solvents but can be purified by precipitation and is well-behaved on silica gel chromatography. The desired porphyrin $\mathbf{1}$ was thus obtained as a brown-violet solid (33\%). 
In the conditions used, the non-substituted fluorenyl arm is stable but, note that alkyl chains have often been introduced on the position-9 of the fluorenyl units by other researchers to increase their solubility. This is presently not necessary for compound $\mathbf{1 .}^{5}$

\subsection{Photophysical properties}

\subsubsection{Electronic spectra}

The UV-visible spectra of $\mathbf{1 , 2}$ and $\mathbf{3}$ exhibit an intense Soret band with a maximum absorption similar around $423 \mathrm{~nm}$ (Fig. 2). This band is slightly red shifted compared to 417 $\mathrm{nm}$ for TPP (5), but not as much as for TFP (4) (426 nm). This tendency in red shifting is observed as well for the Q bands. The $\pi-\pi^{*}$ absorption in the UV range is clearly apparent, due to the presence of fluorene. For compound 2, the four fluorene arms absorb in the UV range with a maximum absorption peak at $272 \mathrm{~nm}$, while for compound 3 possessing eight arms the absorption is stronger with a maximum at $263 \mathrm{~nm}$. These units were absorbing at 270 $\mathrm{nm}$ for new compound 1. For the super porphyrin 1; we can notice that the absorption in the $\mathrm{UV}$ of the fluorenyl groups at $270 \mathrm{~nm}$ is as strong as the Soret band.

(Insert Fig. 2 here please)

Figure 3 shows the absorption spectra of 1, 6, and 10. The absorption spectrum of 1 shows the characteristic peaks at 280 and $300 \mathrm{~nm}$ of compound $\mathbf{1 0}$ in addition to the porphyrin Soret band at $423 \mathrm{~nm}$ and less intense Q-bands, the first of which appear at $513 \mathrm{~nm}$ for compound 6. Obviously, the dendrons and the porphyrin core retain their individual characteristics. These considerations indicate that this molecular pentad $\mathbf{1}$, in which the porphyrin acceptor is linked, via spacers, to four donor dendrons, forms a suitable choice for exploiting the antennae effect between peripheral units and the central core. Effectively, for this effect, it is better to have a multicomponent structure in which the donors and acceptors retain their individual characteristics. Elsewhere for a realistic description of the photosynthetic antenna function, a porphyrin-based model system should exhibit high local concentrations of the light-harvesting chromophores.

\section{(Insert Fig. 3 here please)}

\subsubsection{Emission spectroscopy}

The emission spectrum of compound 1, after excitation in the Soret band reveals a strong red fluorescence with a peak maximum at $656 \mathrm{~nm}$ and a big shoulder at $721 \mathrm{~nm}$ (Fig. 
4). For comparison, the emission spectrum of compound $\mathbf{2}$ is also reported, after excitation in the Soret band, a strong red emission at $663 \mathrm{~nm}$ and a weaker shoulder at $728 \mathrm{~nm}$ is observed (Fig. 4). Concerning, compound 3, after excitation in the Soret band, a strong red emission at $656 \mathrm{~nm}$ and a stronger shoulder at $721 \mathrm{~nm}$ are observed. The emission profile for compounds $\mathbf{1}$ and $\mathbf{3}$ are quite similar. The emission for compound $\mathbf{2}$ possessing only four fluorenyl groups in the para position, is slightly red shifted.

\section{(Insert Fig. 4 here please)}

\subsubsection{Energy transfer}

The emission spectra of compound $\mathbf{1}$ show that the fluorenyl donors transfer energy with high efficiency to the porphyrin acceptor (Figure 5). Excitation of 1 at $300 \mathrm{~nm}$ results mainly in the red emission of porphyrins with a maximum at $656 \mathrm{~nm}$. It is noteworthy that the blue fluorenyl emission is almost completely quenched, and emission is seen predominantly from the porphyrin. Compound 1 shows nice red emission when excited at $300 \mathrm{~nm}$ or $423 \mathrm{~nm}$. Efficiency of energy transfer in this complex process will be studied in details. ${ }^{18}$

The excitation spectrum of compound 1 around $660 \mathrm{~nm}$ reveals that the strong emission from the Soret state is populated when the fluorenyl band is excited. This indicates that excitation over all the $200-650 \mathrm{~nm}$ region leads to the population of the fluorescent excited states of the porphyrin, as the fluorene absorption becomes apparent under such excitation conditions. For comparison, the corresponding excitation spectra of compounds $\mathbf{1}$, $\mathbf{2}$ and $\mathbf{3}$ are shown in fig. 4, and we can see a nicely regular enhancement in the UV region due to the fluorenyl arms.

Thus for these compounds $\mathbf{1 , 2}$ and $\mathbf{3}$, the luminescence can be modulated in a large range of excitation wavelengths from UV to red, to finally obtain the desired red emission.

(Insert Fig. 5 here please)

\subsubsection{Fluorescence quantum yields}

The fluorescence quantum yields of these compounds were next determined by comparing with a calibration standard of compound 5 (TPP) in degassed toluene solution presenting a fluorescence quantum yield of $0.12,{ }^{19}$ preferentially to a benzene solution with a fluorescence quantum yield of $0.13 .^{20}$ [In this latter case, different refractive indices of the solvents used in the standard and sample must be corrected. ${ }^{21}$ In consequence the correction made for the difference in refractive indices of solvents is in this case not necessary.] The quantum yield was calculated from the following equation: 


$$
\Phi_{\mathrm{s}}=\Phi_{\mathrm{TPP}} \times\left(\mathrm{F}_{\mathrm{s}} / \mathrm{F}_{\mathrm{TPP}}\right) \times\left(\mathrm{A}_{\mathrm{TPP}} / \mathrm{A}_{\mathrm{s}}\right) \times\left(\mathrm{n}_{\mathrm{TPP}} / \mathrm{n}_{\mathrm{s}}\right)^{2}
$$

In the above expression, $\boldsymbol{\Phi}_{\mathbf{s}}$ is the fluorescent quantum yield of the new compound, $\mathbf{F}$ is the integration of the emission intensities, $\mathrm{n}$ is the index of refraction of the solution, and $\mathbf{A}$ is the absorbance of the solution at the exciting wavelength. The subscripts TPP and s denote the reference (TPP) and unknown samples, respectively. ${ }^{22}$

Values of quantum yields of free ligands $\mathbf{1 , 2}, \mathbf{3}, \mathbf{4}$ and $\mathbf{5}$ are reported in Table 1. All measurements were obtained under an argon atmosphere to limit photo-oxidative degradation (Table 1). Compounds 1 and 3 present a luminescence quantum yield (14 and $13 \%$ respectively), which is similar to that of the reference 5 (12\%). Further photophysical investigations will be undertaken to rationalize these results. ${ }^{18}$

(Insert Table 1 here please)

\section{Conclusions}

In summary, we have synthesized and characterized a new super-porphyrin 1 bearing sixteen fluorenyl pendant arms at the meso-positions. The photophysical properties are compared to the references first generation dendrimer bearing four units and second generation bearing eight units. These porphyrins emit essentially red light after selective UV or visible irradiation. In case of UV irradiation, these systems comprising a central porphyrin like TPP linked to peripheral photon-harvesting fluorene moieties have been shown to act as efficient antennae. Due to the flexibility of molecular design, dendritic architectures allow site-specific positioning of multiple chromophore units in three-dimensional space; we have found that a large, spherical third-generation dendrimer porphyrin, upon exposure to UV light, shows high energy transfer efficiency from the peripheral aromatic fluorenyl units to the porphyrin core. These results suggest that a judicious choice of meso-aryl dendrons can allow the properties of porphyrins to be optimized for OLEDs, both in terms of efficiency and color tuning. Based on our recent results of anodic electropolymerization of monomers $4,{ }^{10} \mathbf{5}^{23}$ and $\mathbf{6}^{24,25}$ we now expect to obtain a polymeric $3 \mathrm{D}$ network composed of spherical chromophores after connections of the sixteen fluorenyl pendant arms. This should allow growing a dendrimer-polymeric 3D structure from such macrocycles, possessing several connecting points for each monomer. This family of compounds constitutes therefore an interesting building block to access new red emissive organic materials. 


\section{Experimental}

\subsection{General}

All reactions were performed under argon and were magnetically stirred. Solvents were distilled from appropriate drying agent prior to use, $\mathrm{CH}_{2} \mathrm{Cl}_{2}$ from $\mathrm{CaH}_{2}, \mathrm{CHCl}_{3}$ from $\mathrm{P}_{2} \mathrm{O}_{5}$ and all other solvents were HPLC grade. Commercially available reagents were used without further purification unless otherwise stated. ${ }^{1} \mathrm{H}$ NMR and ${ }^{13} \mathrm{C} \mathrm{NMR}$ in $\mathrm{CDCl}_{3}$ were recorded using Bruker 200 DPX, 300 DPX and 500 DPX spectrometers. The chemical shifts are referenced to internal TMS. The assignments were performed by 2D NMR experiments: COSY (Correlation Spectroscopy), HMBC (Heteronuclear Multiple Bond Correlation) and HMQC (Heteronuclear Multiple Quantum Coherence). UV spectra were recorded on UVIKON XL from Biotek instruments. PL emission was recorded on a Photon Technology International (PTI) apparatus coupled on an 814 Photomultiplier Detection System, Lamp Power Supply 220B and MD-5020. Pyrrole and 2-fluorenecarboxaldehyde were purchased from Aldrich and were used as received. References $\mathbf{T F P}=$ tetrafluorenylporphyrin, $\mathbf{T P P}=$ tetraphenylporphyrin.

\subsection{Synthesis of the arms}

4.2.1. Synthesis of 2-bromomethyl-fluorene (8) from 2-hydroxyl-methyl-fluorene was described earlier. ${ }^{17}$

${ }^{1} \mathrm{H}-\mathrm{NMR}\left(200 \mathrm{MHz}, \mathrm{CDCl}_{3}\right): 7.81\left(\mathrm{~d},{ }^{3} J_{\mathrm{HH}}=8.0 \mathrm{~Hz}, 1 \mathrm{H}\right), 7.75\left(\mathrm{~d},{ }^{3} J_{\mathrm{HH}}=7.7 \mathrm{~Hz}, 1 \mathrm{H}\right)$, $7.59\left(\mathrm{~d},{ }^{3} J_{\mathrm{HH}}=8.8 \mathrm{~Hz}, 2 \mathrm{H}\right), 7.43\left(\mathrm{~d},{ }^{3} J_{\mathrm{HH}}=7.9 \mathrm{~Hz}, 1 \mathrm{H}\right), 7.38\left(\mathrm{~d},{ }^{3} J_{\mathrm{HH}}=8.0 \mathrm{~Hz}, 1 \mathrm{H}\right), 7.37(\mathrm{~s}, 1 \mathrm{H})$, 4.61 (s, 2H, $\mathrm{CH}_{\mathbf{2}}-\mathrm{Br}$ ), 3.94 (s, 2H, $\mathrm{CH}_{\mathbf{2 f l u o r e n e}}$ ).

\subsubsection{Synthesis of alcool 9}

To a solution of the commercial 5-hydroxymethyl-benzen-1,3-diol (0.98 g, 7.02 $\mathrm{mmol}$ ) and 2-bromomethyl-fluorene $8(4.00 \mathrm{~g}, 15.44 \mathrm{mmol})$ in $20 \mathrm{~mL}$ of dry acetone was added $\mathrm{K}_{2} \mathrm{CO}_{3}(3.87 \mathrm{~g}, 28.0 \mathrm{mmol})$ and 18-crown-6 $(1.85 \mathrm{~g}, 7.02 \mathrm{mmol})$. This solution is stirred under argon at reflux during 12 hours. The reaction mixture was cooled at room 
temperature, filtered and evaporated to dryness. The crude product was partitioned between water and $\mathrm{CH}_{2} \mathrm{Cl}_{2}$, and the organic phase was dried over $\mathrm{MgSO}_{4}$ and evaporated to dryness. The residue was purified by column chromatography on silica gel $\left(\mathrm{CH}_{2} \mathrm{Cl}_{2}\right)$ to yield $2.47 \mathrm{~g}$ of a white solid $(71 \%)$.

${ }^{1} \mathrm{H}-\mathrm{NMR}\left(200 \mathrm{MHz}, \mathrm{CDCl}_{3}\right): \delta 7.81\left(\mathrm{~d},{ }^{3} \mathrm{~J}_{\mathrm{HH}}=7.5 \mathrm{~Hz}, 4 \mathrm{H}, \mathrm{H}_{4},-5^{\prime}\right), 7.64\left(\mathrm{~s}, 2 \mathrm{H}, \mathrm{H}_{1^{\prime}}\right)$,

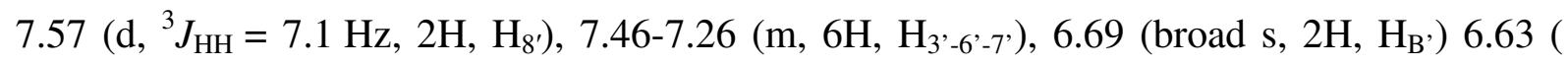

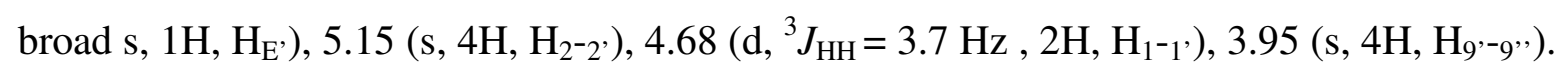

\subsubsection{Synthesis of final dendron 10}

To a THF solution $(100 \mathrm{~mL})$ of alcohol 9 (1.60 g, $3.22 \mathrm{mmol})$ was added carbon tetrabromide ( $1.28 \mathrm{~g}, 38.7 \mathrm{mmol}$ ) followed by the portion-wise addition of triphenylphosphine $(1.01 \mathrm{~g}, 38.7 \mathrm{mmol})$. The mixture was stirred at $0^{\circ} \mathrm{C}$ for $1 \mathrm{~h}$, and $2 \mathrm{~h}$ at room temperature. The crude product was partitioned between water (to neutralize $\mathrm{CBr}_{4}$ ) and $\mathrm{CH}_{2} \mathrm{Cl}_{2}$ then the organic phase was dried over $\mathrm{MgSO}_{4}$ and evaporated to dryness. The residue was purified by column chromatography on silica gel $\left(5: 1\right.$ pentane/ $\left.\mathrm{CH}_{2} \mathrm{Cl}_{2}\right)$ to give $1.44 \mathrm{~g}(80 \%)$ of $\mathbf{1 0}$ as a white solid.

${ }^{1} \mathrm{H}-\mathrm{NMR}\left(200 \mathrm{MHz}, \mathrm{CDCl}_{3}\right): \delta 7.81\left(\mathrm{~d},{ }^{3} J_{\mathrm{HH}}=7.5 \mathrm{~Hz}, 4 \mathrm{H}, \mathrm{H}_{4^{\prime}-5^{\prime}}\right), 7.63\left(\mathrm{~s}, 2 \mathrm{H}, \mathrm{H}_{1^{\prime}}\right)$,

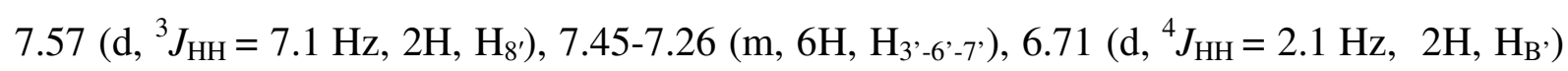

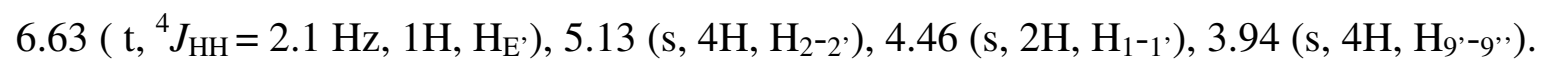

\subsection{Synthesis of porphyrins}

\subsubsection{Synthesis of porphyrin 6}

Tetrakis(3,5-dimethoxyphenyl)porphyrin 6 (OOMePP) was prepared from pyrrole and the respective aromatic aldehyde using Adler-Longo condensation conditions. ${ }^{26}$

\subsubsection{Synthesis of porphyrin 7}

Tetrakis(3,5-dihydroxyphenyl)porphyrin 7 (OOHPP) was prepared by boron tribromide deprotection of tetrakis(3,5-dimethoxyphenyl)porphyrin 6.

\subsubsection{Synthesis of super porphyrin SOFP 1}

The bromide dendron, compound $\mathbf{1 0}$ (500 mg, $0.90 \mathrm{mmol})$, tetrakis (3,5dihydroxyphenyl)-porphyrin, 7 (74 mg, $0.09 \mathrm{mmol}), \mathrm{K}_{2} \mathrm{CO}_{3}(219 \mathrm{mg}, 1.59 \mathrm{mmol})$ and 18 crown-6 (26 mg, $0.01 \mathrm{mmol})$, were dissolved in $20 \mathrm{~mL}$ of dry THF and stirred under argon at 
reflux for 4 days. Then the reaction mixture was cooled to room temperature and evaporated to dryness. The crude product was partitioned between water $(200 \mathrm{~mL})$ and dichloromethane $(200 \mathrm{~mL})$, the aqueous layer was extracted with dichloromethane $(200 \mathrm{~mL})$, and the combined extracts were dried by $\mathrm{MgSO}_{4}$ and evaporated to dryness. Purification by flash chromatography eluting with 4:6 pentane/dichloromethane gave the super-porphyrin $\mathbf{1}$, as a violet powder (150 mg, yield $33 \%)$.

${ }^{1} \mathrm{H}-\mathrm{NMR}$ ( assignments aided by COSY) $\left(\mathrm{CDCl}_{3}\right): \delta 8.85$ (s, 8H, pyrrole), 7.55 (d, $\left.{ }^{3} J_{\mathrm{HH}}=7.4 \mathrm{~Hz}, 16 \mathrm{H}, \mathrm{H}_{5^{\prime}}\right), 7.49\left(\mathrm{~d},{ }^{3} J_{\mathrm{HH}}=7.8 \mathrm{~Hz}, 16 \mathrm{H}, \mathrm{H}_{4^{\prime}}\right), 7.45\left(\mathrm{~d},{ }^{4} J_{\mathrm{HH}}=2.2 \mathrm{~Hz}, 8 \mathrm{H}, \mathrm{H}_{\mathrm{B}}\right)$, $7.35\left(\mathrm{~s}, 16 \mathrm{H}, \mathrm{H}_{1^{\prime}}\right), 7.34\left(\mathrm{~d},{ }^{3} J_{\mathrm{HH}}=7.4 \mathrm{~Hz}, 16 \mathrm{H}, \mathrm{H}_{8^{\prime}}\right), 7.22\left(\mathrm{t},{ }^{3} J_{\mathrm{HH}}=6.7 \mathrm{~Hz}, 16 \mathrm{H}, \mathrm{H}_{6}\right), 7.16(\mathrm{t}$, $\left.{ }^{3} J_{\mathrm{HH}}=7.3 \mathrm{~Hz}, 16 \mathrm{H}, \mathrm{H}_{7^{\prime}}\right), 7.15,\left(\mathrm{~d},{ }^{3} J_{\mathrm{HH}}=7.1 \mathrm{~Hz}, 16 \mathrm{H}, \mathrm{H}_{3^{\prime}}\right), 7.04\left(\mathrm{t},{ }^{4} J_{\mathrm{HH}}=2.1 \mathrm{~Hz}, 4 \mathrm{H}, \mathrm{H}_{\mathrm{E}}\right)$, $6.70\left(\mathrm{~d},{ }^{4} J_{\mathrm{HH}}=2.1 \mathrm{~Hz}, 16 \mathrm{H}, \mathrm{H}_{\mathrm{B}}\right), 6.59\left(\mathrm{t},{ }^{4} J_{\mathrm{HH}}=2.1 \mathrm{~Hz}, 8 \mathrm{H}, \mathrm{H}_{\mathrm{E}}\right), 5.07\left(\mathrm{~s}, 16 \mathrm{H}, \mathrm{H}_{\mathrm{H} 1-\mathrm{H} 1}{ }^{\prime}\right), 4.92$ (s, 32H, $\mathrm{H}_{\mathrm{H} 2-\mathrm{H} 2^{\prime}}$ ), 3.66 (s, 32H, $\mathrm{H}_{9^{\prime}-9^{\prime}}$ ), -2.72 (broad s, 2H, NH).

${ }^{13} \mathrm{C}-\mathrm{NMR}\left(\mathrm{CDCl}_{3}\right): \delta 160.30\left(\mathrm{C}_{\mathrm{D}^{\prime}}\right), 157.91\left(\mathrm{C}_{\mathrm{D}}\right), 143.54\left(\mathrm{C}_{9},\right), 143.32\left(\mathrm{C}_{4}{ }^{\prime \prime}\right), 143.00$

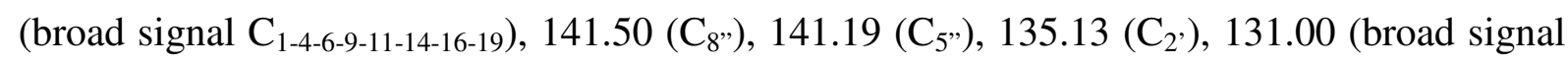

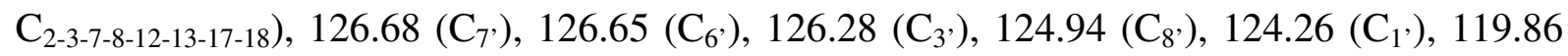
$\left(\mathrm{C}_{5}{ }^{\prime}\right), 119.76\left(\mathrm{C}_{4}\right), 115.36\left(\mathrm{C}_{\mathrm{B}}\right), 106.45\left(\mathrm{C}_{\mathrm{B}^{\prime}}\right), 102.42\left(\mathrm{C}_{\mathrm{E}}\right), 102.41\left(\mathrm{C}_{5-10-15-20}\right), 101.86\left(\mathrm{C}_{\mathrm{E}^{\prime}}\right)$, $70.38\left(\mathrm{C}_{\mathrm{H} 1}\right), 70.31\left(\mathrm{C}_{\mathrm{H} 2}\right), 36.67\left(\mathrm{C}_{9^{\prime}}\right)$.

Analysis: calcd for $\mathrm{C}_{324} \mathrm{H}_{238} \mathrm{~N}_{4} \mathrm{O}_{24} .3 \mathrm{CHCl}_{3}$ : C, 79.67; H, 4.93; N, 1.14 found C, 79.50; $\mathrm{H}$, 5.36; N, 0.29. MALDI TOF-MS calcd for $\mathrm{C}_{324} \mathrm{H}_{238} \mathrm{~N}_{4} \mathrm{O}_{24}: 4572.4645[\mathrm{MH}]^{+}$, found

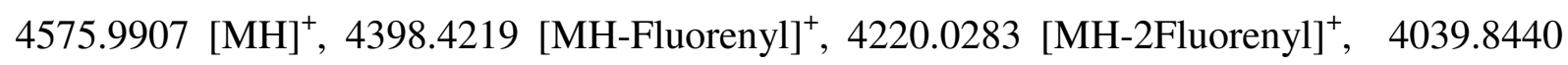
[MH-3Fluorenyl] ${ }^{+}$. UV-vis $\left(\mathrm{CH}_{2} \mathrm{Cl}_{2}\right): \lambda_{\max } \mathrm{nm}\left(10^{-3} \varepsilon\right) \quad 270$ (421, fluorene), 304 (194, fluorene), 423 (433, Soret band), $517\left(17, \mathrm{Q}_{1}\right), 552\left(6, \mathrm{Q}_{2}\right), 590\left(5, \mathrm{Q}_{3}\right), 647\left(3, \mathrm{Q}_{4}\right)$.

\section{Acknowledgements}

The authors are grateful to S. Sinbandhit (CRMPO), G. Simonneaux and P. Le Maux (ICMVUMR 6226) for their technical assistance and helpful discussions.

\section{References}

1 Abraham, R. J.; Hawkes, G. E.; Hudson, M. F.; Smith, K. M. J. Chem. Soc., Perkin. Trans. II 1975, 204-211.

2 Fonda, H. N.; Gilbert, J. V.; Cormier, R. A.; Sprague, J. R.; Kamioka, K.; Connolly, J. S. J. Phys. Chem. 1993, 97, 7024-7033.

3 Toeibs, A.; Haeberle, N. Justus Liebigs Ann. Chem. 1968, 718, 183-187. 
Li, B.; Xu, X.; Sun, M.; Fu, Y.; Yu, G.; Liu, Y.; Bo, Z. Macromolecules 2006, 39, 456-461.

Li, B.; Li, J.; Fu, Y.; Bo, Z. J. Am. Chem. Soc. 2004, 126, 3430-3431.

Harth, E. M.; Hecht, S.; Helms, B.; Malmstrom, E. E.; Fréchet, J. M.; Hawker, C. J. J. Am. Chem. Soc. 2002, 124, 3926-3938.

7 Dichtel, W. R.; Serin, J. M.; Edder, C.; Fréchet, J. M. J. Am. Chem. Soc. 2004, 126, 5380-5381.

8 Oar, M. A.; Serin, J. M.; Fréchet, J. M. Chem. Mater. 2006, 18, 3682-3692.

9 Sun, M.; Bo, Z. Journal of Polymer Science: Part A: Polymer Chemistry 2006, 45, 111-124.

10 Paul-Roth, C.; Rault-Berthelot, J.; Simonneaux, G. Tetrahedron 2004, 60, 12169-12175.

11 Paul-Roth, C. O.; Simonneaux, G. Tetrahedron Lett. 2006, 47, 3275-3278.

Paul-Roth, C. O.; Simonneaux , G. C.R. Acad. Sci., Ser. IIb: Chim. 2006, 9, 1277-1286.

Paul-Roth, C.; Williams, G.; Letessier, J.; Simonneaux , G. Tetrahedron Lett. 2007, 48, 4317-4322.

Drouet, S.; Paul-Roth, C.; Williams, J. A. G.; Fattori, V. manuscript in preparation 2009.

Ren, X.; Ren, A.; Feng, J.; Sun, C. Journal of Photochemistry and Photobiology A: Chemistry 2009, 203, 92-99.

Jiang, D.-L.; Aida, T. J. Am. Chem. Soc. 1998, 120, 10895-10901.

Drouet, S.; Paul-Roth, C.; Simonneaux, G. Tetrahedron 2009, 65, 2975-2981.

Drouet, S.; Williams, J. A. G.; Paul-Roth, C. 2009, manuscript in preparation.

Owens, J. W.; Smith, R.; Robinson, R.; Robins, M. Inorg. Chim. Acta 1998, 279, 226-231.

Zang, X. H.; Xie, Z. Y.; Wu, F. P.; Zhou, L. L.; Wong, O. Y.; Lee, C. S.; Kwong, H. L.; Lee, S. T.; Wu, S. K. Chem. Phys. Lett. 2003, 382, 561-566.

Quimby, D. J.; Longo, F. R. J. Am. Chem. Soc. 1975, 97, 5111-5117.

Demas, J. N.; Crosby, G. A. J. Phys. Chem. 1971, 75, 991-1024.

Paul-Roth, C.; Rault-Berthelot, J.; Simonneaux, G.; Poriel, C.; Abdalilah, M.; Letessier, J. J.

Electroanal. Chem. 2006, 597, 19-27.

Rault-Berthelot, J.; Paul-Roth, C.; Poriel, C.; Juillard, S.; Ballut, S.; Drouet, S.; Simonneaux, G. J. Electroanal. Chem. 2008, 623, 204-214.

Drouet, S.; Ballut, S.; Rault-Berthelot, J.; Turban, P.; Paul-Roth, C. Thin Solid Films 2009, 517, 54745481.

Kim, J. B.; Adler, A. D.; Longo, F. R. In : The Porphyrins; Dolphin, D., Ed.; Academic Press: Newyork 1978, Vol. 1, Part A, p 85. 


\section{Schemes and Figures Captions}

Scheme 1: $\quad$ Synthesis of porphyrins 6, 7 and SOFP 1

Scheme 2: $\quad$ Synthesis of dendrons 9 and $\mathbf{1 0}$

Figure 1: $\quad$ Compounds 1, 2, 3, 4, 5, 6 and 7

Figure 2: $\quad$ UV-visible absorption spectra for compounds $\mathbf{1}$ (green), 2 (red) and $\mathbf{3}$ ( blue), in $\mathrm{CH}_{2} \mathrm{Cl}_{2}$ at $25^{\circ} \mathrm{C}$

( 2.0 $10^{-6} \mathrm{M}$ for $\mathbf{1}$ and normalized to the same absorbance for $\mathbf{2}$ and $\mathbf{3}$ ).

Figure 3: $\quad$ Absorption spectra of $\mathbf{6}$ (red), $\mathbf{1 0}$ (blue), and $\mathbf{1}$ (green) in chloroform at room temperature. The spectrum of $\mathbf{1 0}$ is normalized to the spectrum of $\mathbf{1}$ at $300 \mathrm{~nm}$, while the height of the Soret band at $420 \mathrm{~nm}$ in the spectrum of $\mathbf{6}$ is normalized to the height of the Soret band of $\mathbf{1}$.

Figure 4: $\quad$ Photoluminescence spectra of free ligands 1 (plain green), 2 (plain red) and $\mathbf{3}$ (plain blue) in $\mathrm{CH}_{2} \mathrm{Cl}_{2}$ solution $\left(\sim 1.010^{-6} \mathrm{M}\right)$, at $25^{\circ} \mathrm{C}$, the emission spectra were cut above $800 \mathrm{~nm}$.

Excitation spectra of compounds $\mathbf{1}$ (dashed green), $\mathbf{2}$ (dashed red) and $\mathbf{3}$ (dashed blue) at 660 $\mathrm{nm}$.

Figure 5: $\quad$ Fluorescence spectra of $\mathbf{1}$ in chloroform at room temperature under single photon excitation conditions. A near complete quenching of the donor emission is observed upon excitation of $\mathbf{1}$ at $300 \mathrm{~nm}$ (blue), resulting in a significant porphyrin emission from 1, compared to direct emission of 1 at $423 \mathrm{~nm}$ (red).

Figure 6: $\quad$ Hydrogen and carbon atom-labeling for dendrons 9, 10 and for the porphyrin 1

Table 1: Photophysical properties of the fluorenyl porphyrins $\mathbf{1}, \mathbf{2}$ and $\mathbf{3}$ in dilute $\mathrm{CH}_{2} \mathrm{Cl}_{2}$ solution at $298 \mathrm{~K}$, and of $\mathbf{4}$ and $\mathbf{5}$, under the same conditions for comparison 

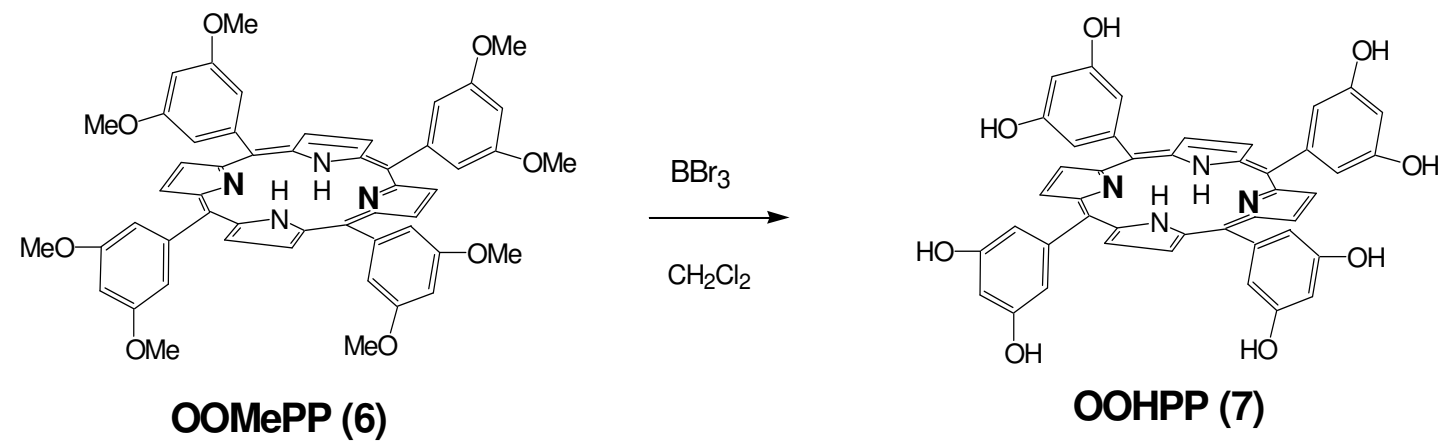

Yield $93 \%$
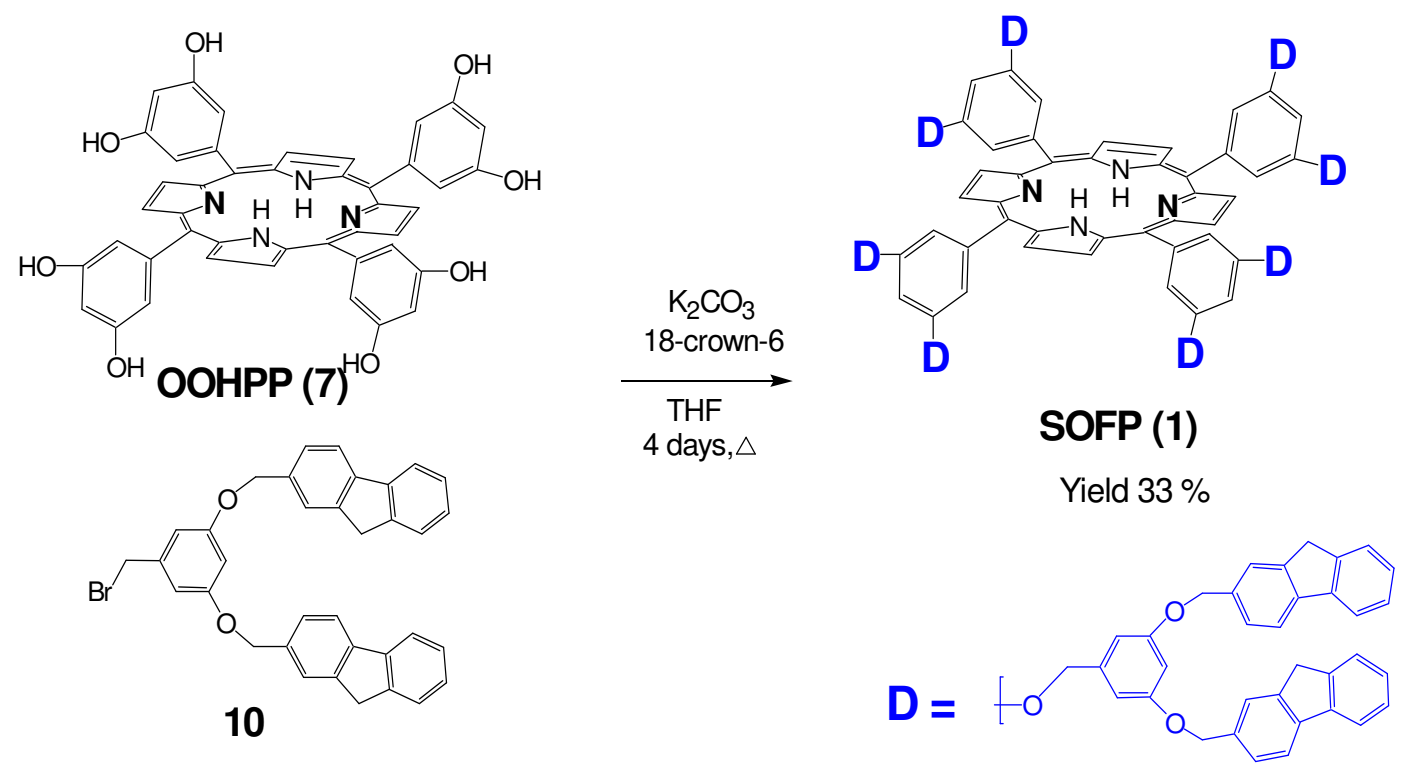

Scheme 1: Synthesis of porphyrins 6, 7 and SOFP 1 

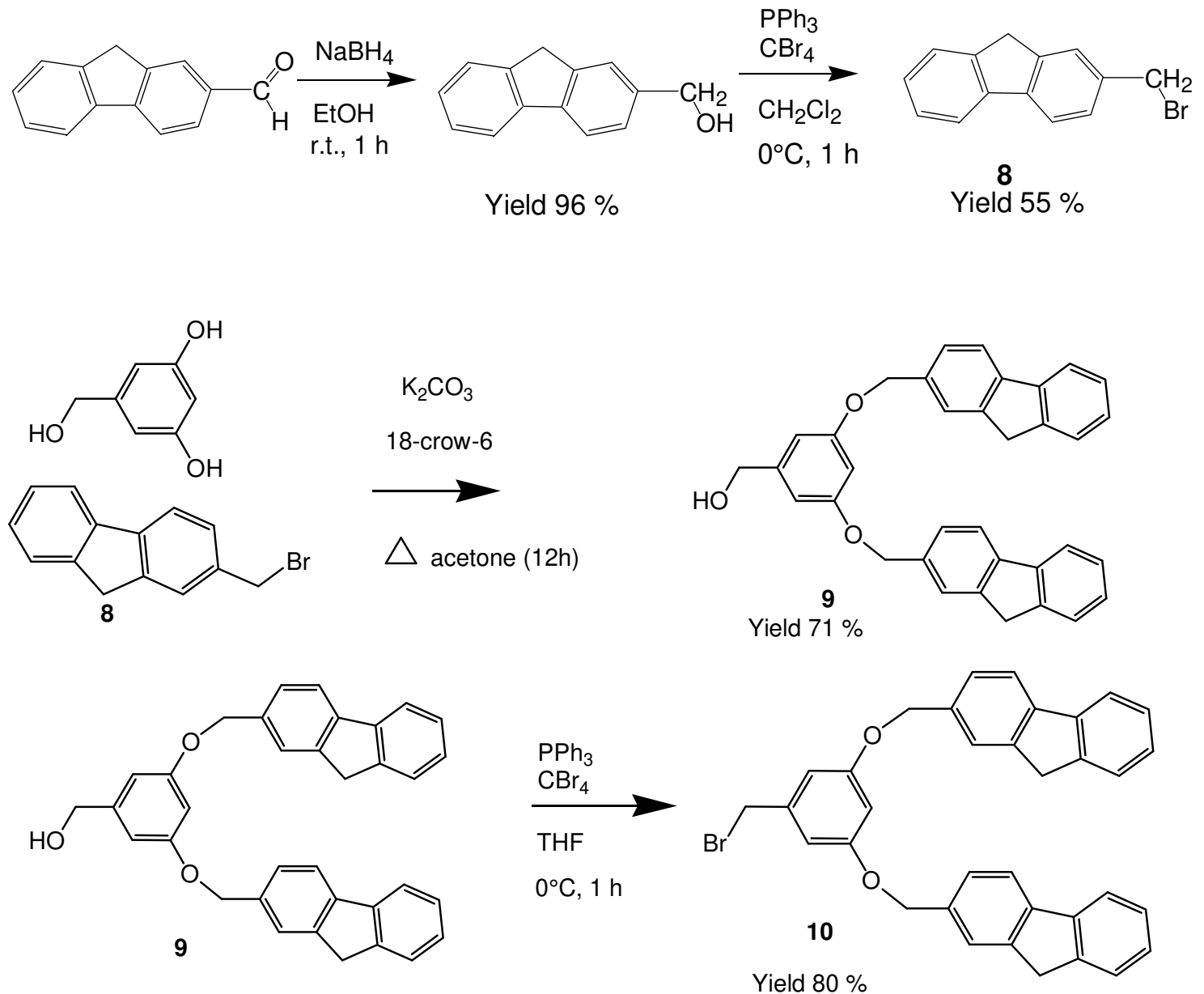

Scheme 2: Synthesis of dendrons 9 and $\mathbf{1 0}$ 


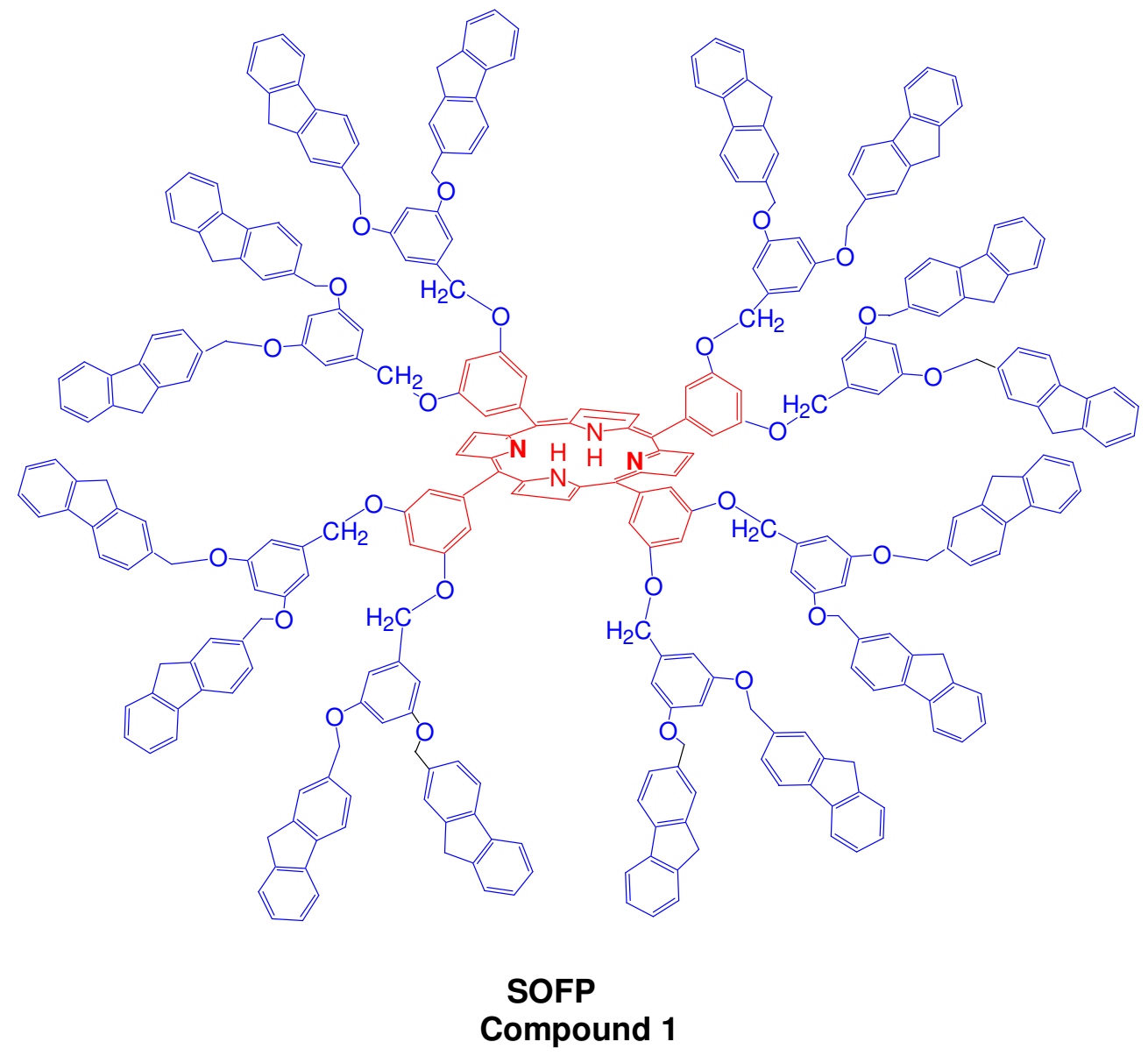

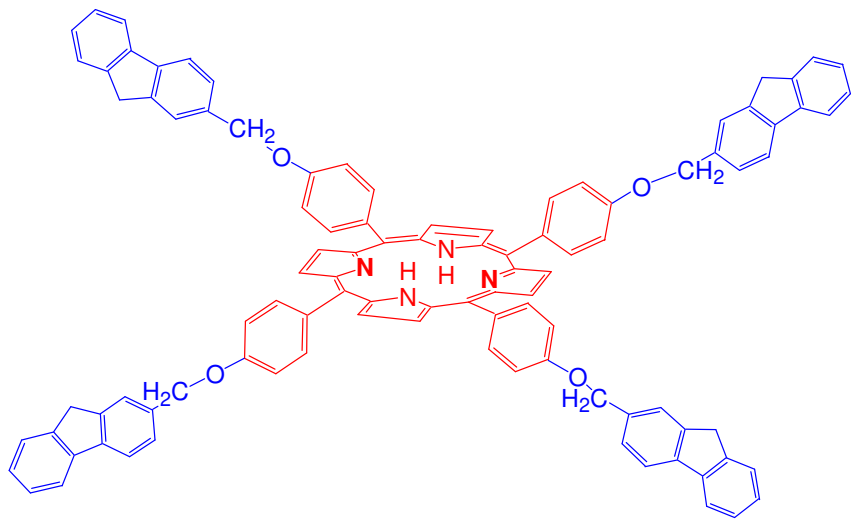

TOFP

Compound 2

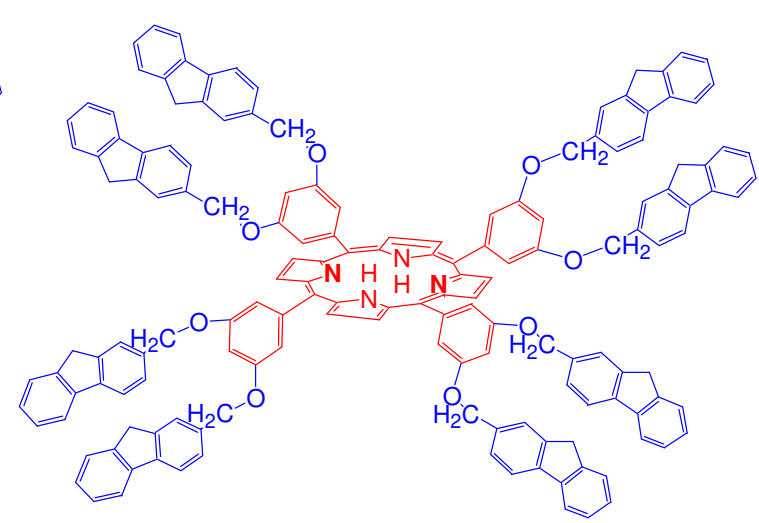

OOFP

Compound 3 


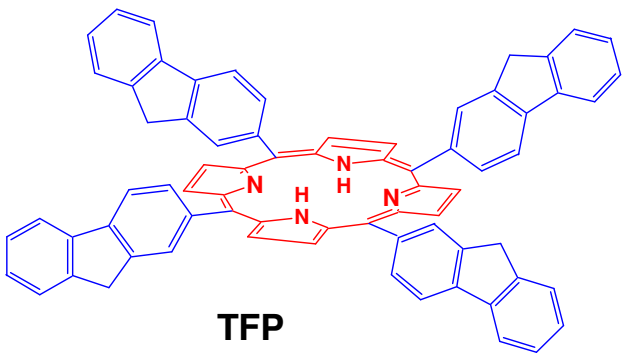

Compound 4

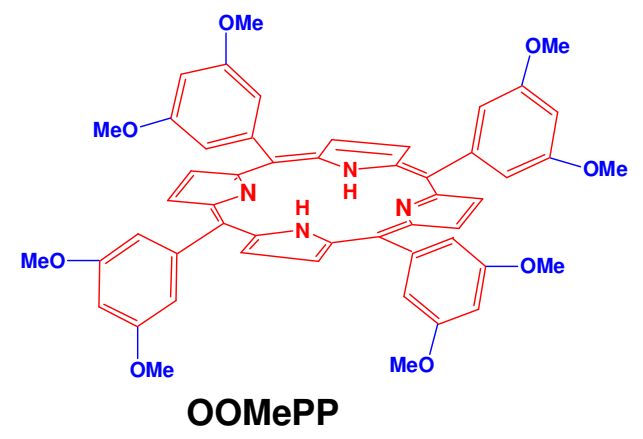

Compound 6

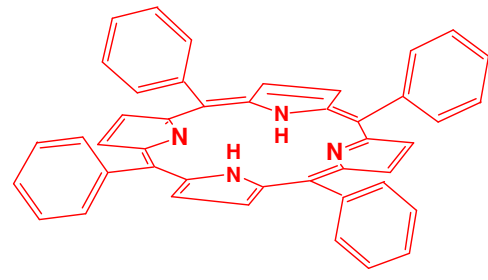

TPP

Compound 5

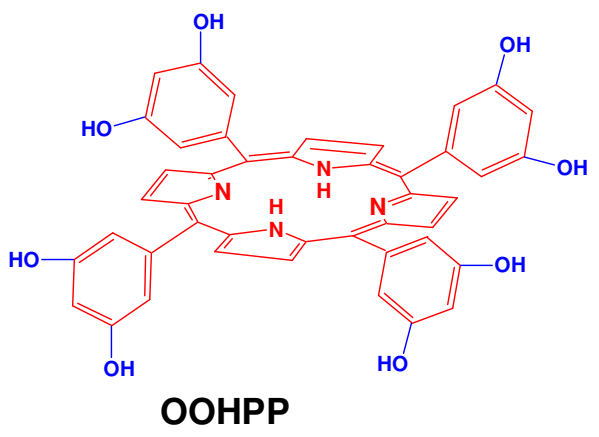

Compound 7

Figure 1 


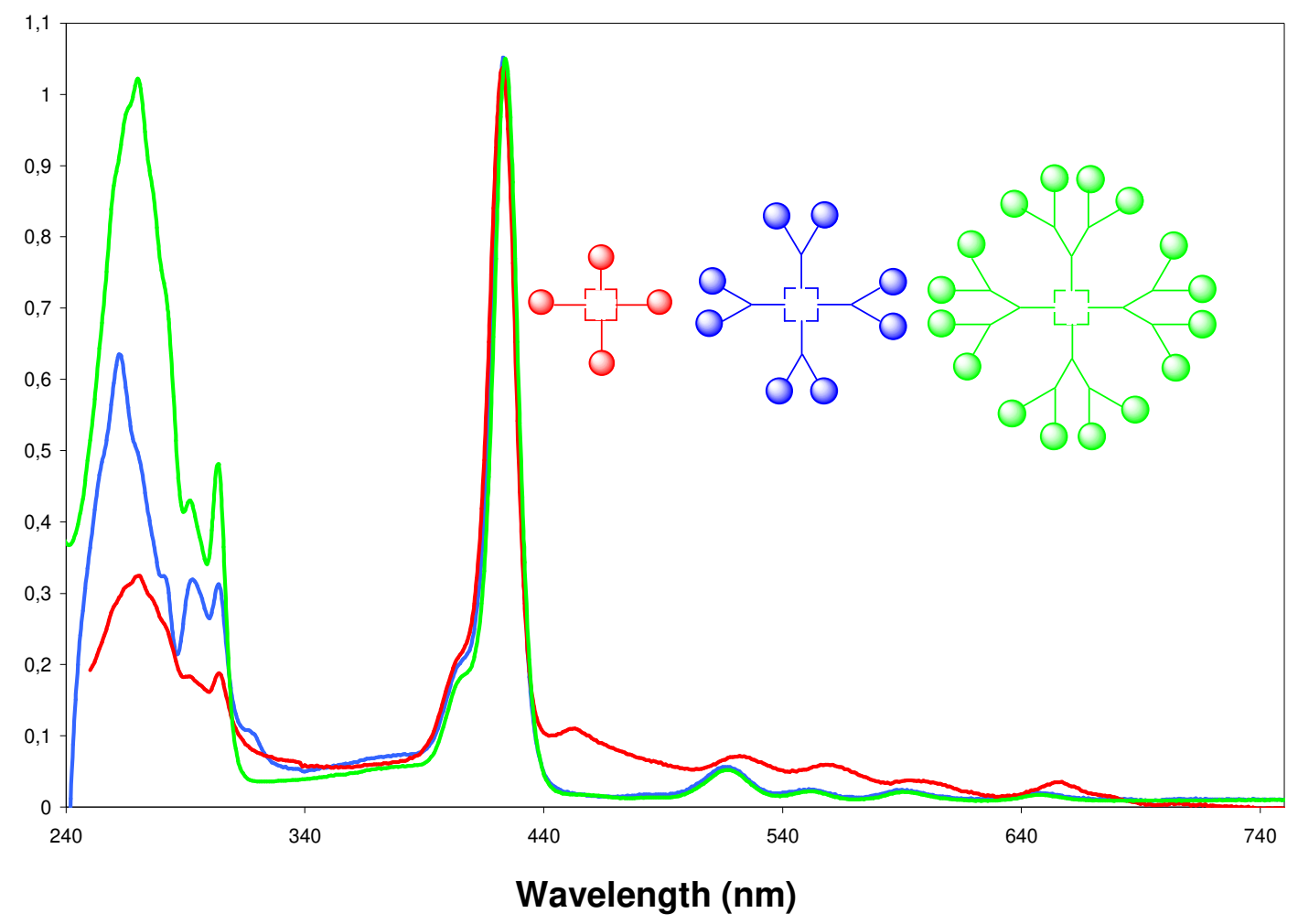

Figure 2 


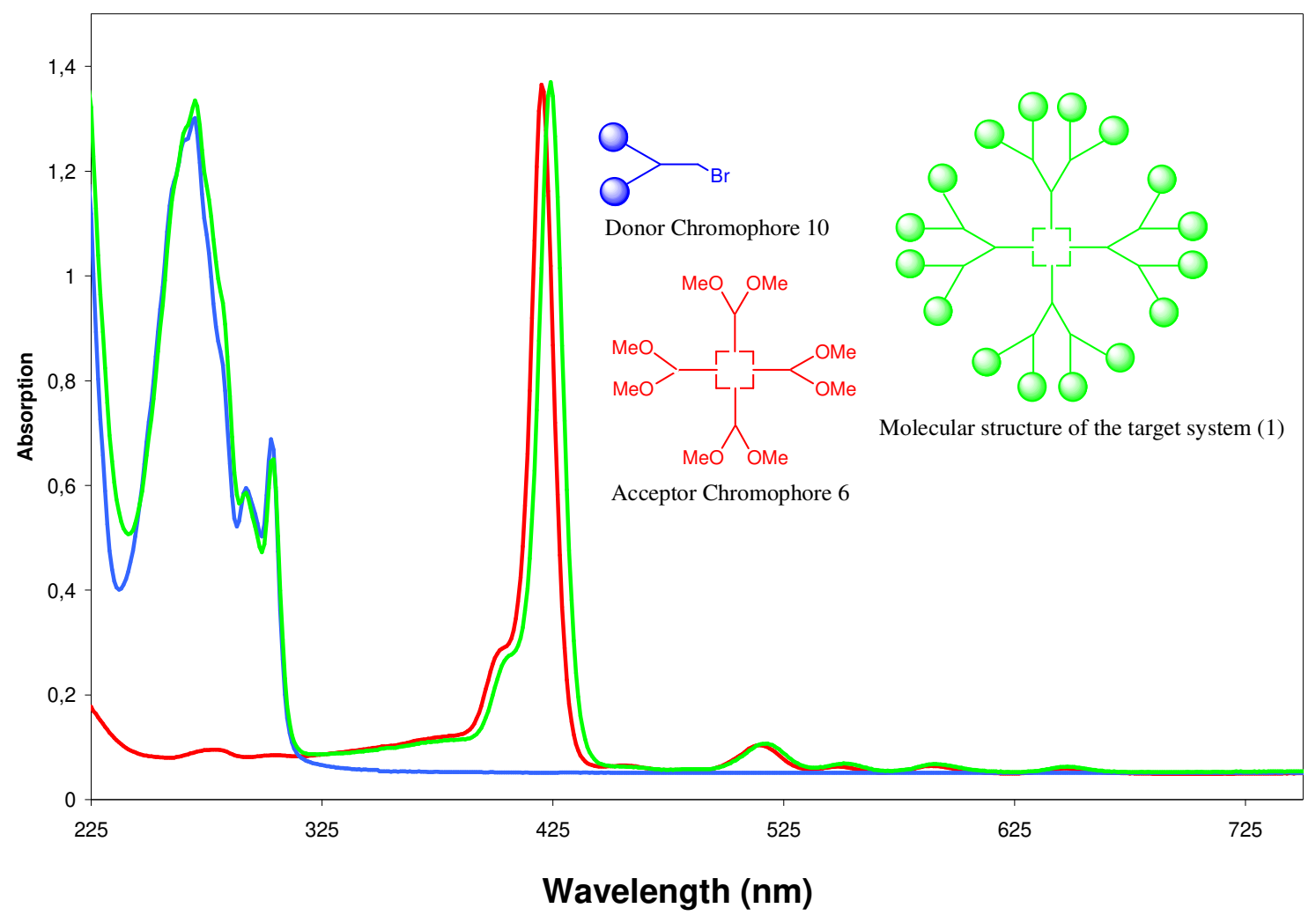

Figure 3 


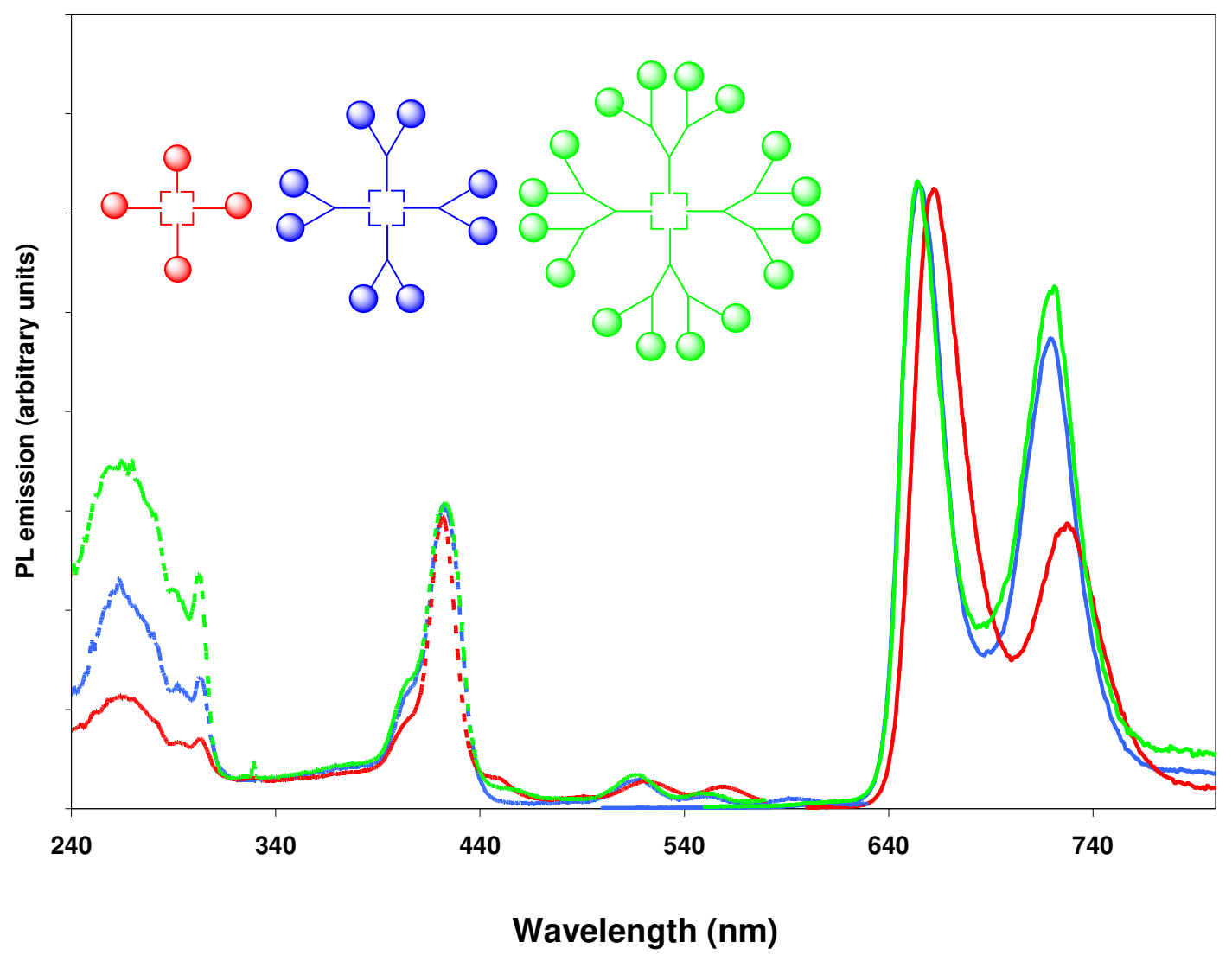

Figure 4 


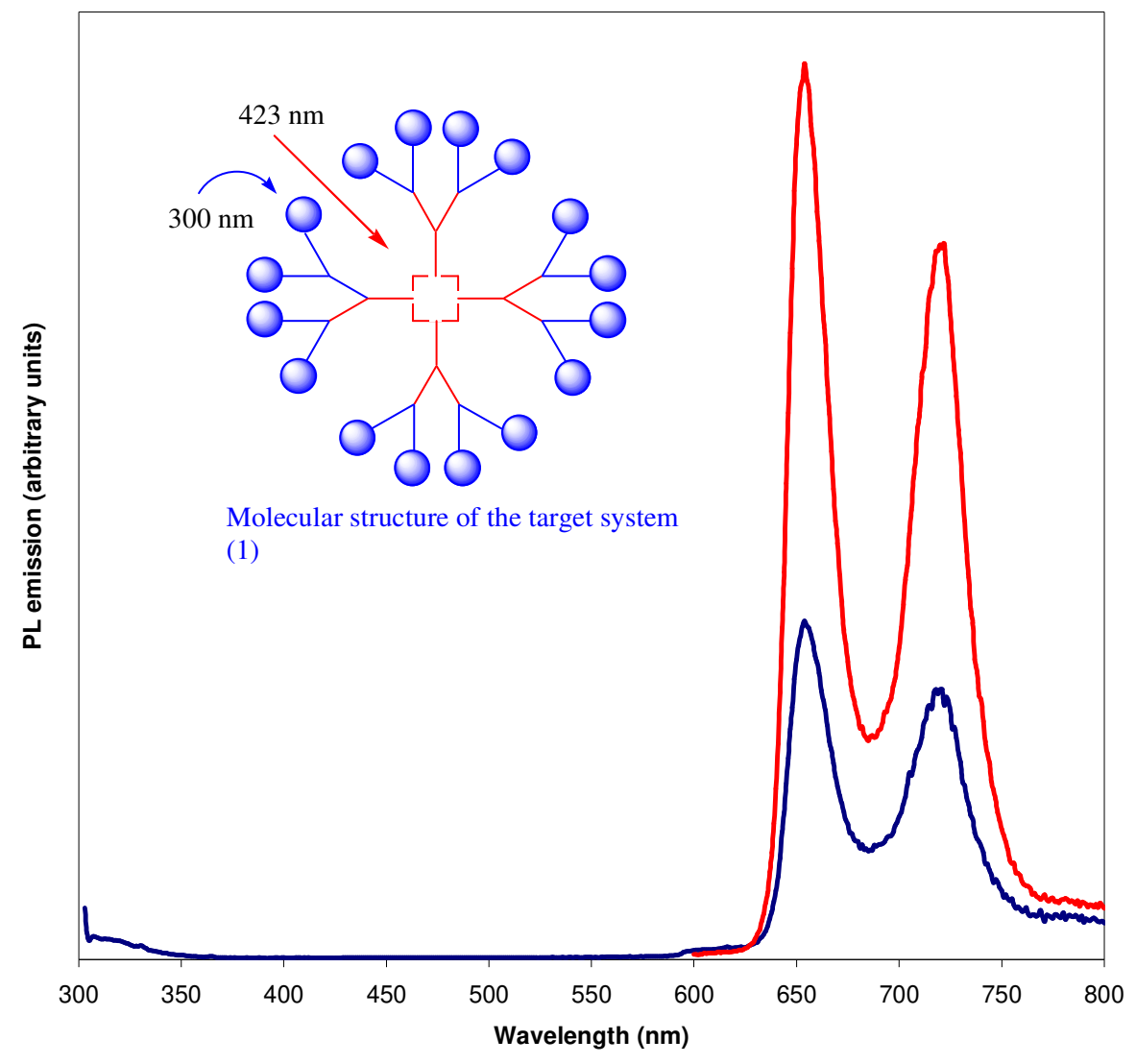

Figure 5 


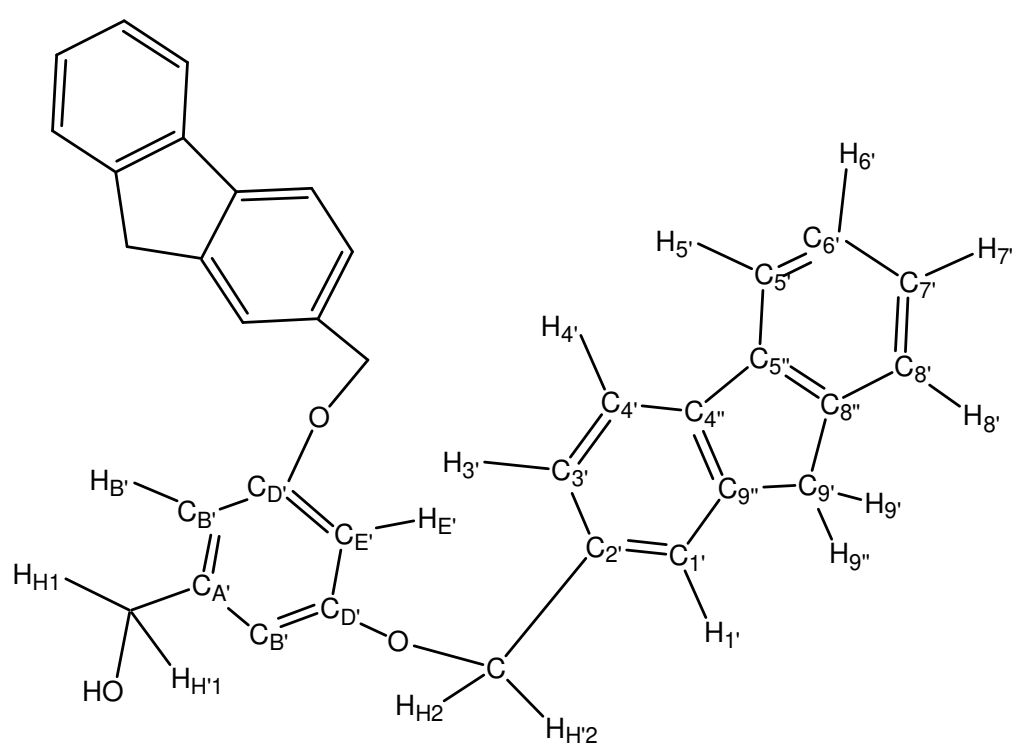

Compound 9

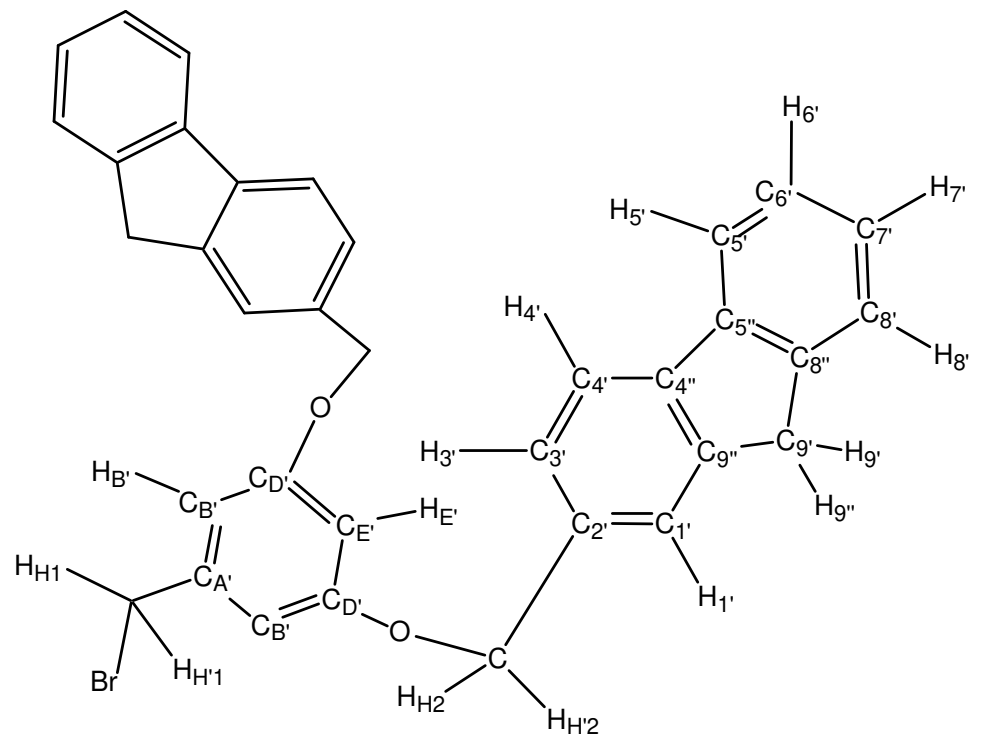

Compound 10 


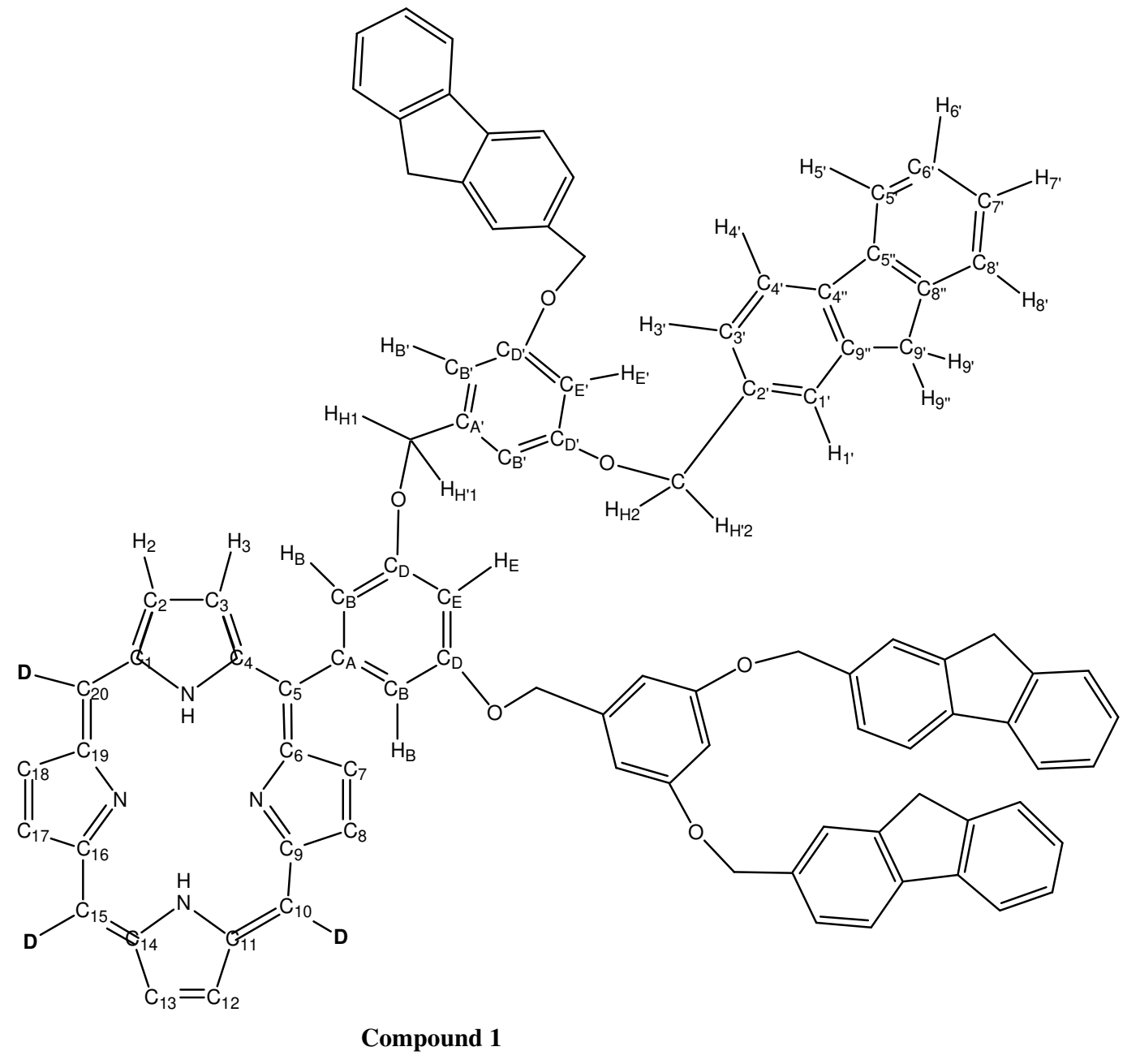

Figure 6 
Table 1: Photophysical properties of the fluorenyl porphyrins $\mathbf{1}, \mathbf{2}$ and $\mathbf{3}$ in dilute $\mathrm{CH}_{2} \mathrm{Cl}_{2}$ solution at $298 \mathrm{~K}$, and of $\mathbf{4}$ and $\mathbf{5}$, under the same conditions for comparison

\begin{tabular}{|l|c|c|c|c|c|}
\hline Porphyrin & SOFP (1) & TOFP (2) & OOFP (3) & TFP (4) & TPP (5) \\
\hline $\begin{array}{l}\lambda_{\max } / \mathrm{nm}^{(a)} \\
\text { Soret band }\end{array}$ & 423 & 423 & 423 & 426 & 417 \\
\hline$\lambda_{\mathrm{em}} / \mathrm{nm}$ & 656,721 & 663,728 & 656,721 & 663,730 & 653,721 \\
\hline$\Phi_{\mathrm{f}}{ }^{(b)}$ & 0.14 & 0.10 & 0.13 & 0.24 & 0.12 \\
\hline
\end{tabular}

${ }^{(a)}$ Wavelengths of the absorption maxima in the Soret or B band region (400-450 $\mathrm{nm}$ range)

${ }^{(b)}$ Fluorescence quantum yields in degassed solution, using TPP in toluene as standard, following excitation into the Soret bands 